RU Развитие отечественной системы дополнительного образования исторические параллели

\author{
Дьячин А. С.
}

\begin{abstract}
Аннотация. Цель исследования - проведение сравнительного анализа системы дополнительного образования школьников Советского Союза конца 50-х - начала 60-х годов и современной России. В работе особое внимание уделяется установлению логических связей ключевых аспектов дополнительного образования: приоритетных направлений, реализации социального заказа государства, социализации личности. Рассмотрены и проанализированы основные нормативные документы, регламентирующие деятельность институтов дополнительного образования выбранных периодов. Научная новизна исследования состоит в сравнении дополнительного образования школьников СССР конца 50-х - начала 60-х годов XX века с современностью с точки зрения организации образовательного процесса и реализации социального заказа общества и государства, а не на основе идеологического аспекта. Результаты исследования показывают, что организация процесса обучения в учреждениях дополнительного образования 1950-1960-х годов не потеряла своей актуальности, но была модернизирована и адаптирована к современным условиям.
\end{abstract}

\title{
EN Development of the Russian System of Additional Education - Historical Parallels
}

\section{Dyachin A. S.}

\begin{abstract}
The research aims to carry out a comparative analysis of the system of schoolchildren's additional education in the Soviet Union in the late 50s - early 60s and in modern Russia. The paper pays special attention to establishing a logical link between the key aspects of additional education: priority areas, delivery of social services under the government social-sector procurement, an individual's socialisation. The main normative documents regulating activity of institutions of additional education during the chosen time periods are considered and analysed. Scientific novelty of the research lies in comparing schoolchildren's additional education in the USSR in the late 1950s - early 1960s with that of the present time from the viewpoint of educational process organisation and social services delivery under the government and society social-sector procurement rather than basing on the ideological aspect. The research findings show that educational process organisation in institutions of additional education in the 1950s and 1960s has not lost its relevance but has been modernised and adapted to the contemporary conditions.
\end{abstract}

\section{Введение}

Актуальность. Дополнительное образование, являясь составной и вариативной частью структуры общего образования, направлено на повышение мотивации к обучению и формирование потребности в творчестве и познании, создает условия для личностного и профессионального самоопределения. Данный компонент образовательной системы выступает в качестве агента социализации и помогает успешно адаптироваться и реализовать себя в социуме большому количеству людей. Обращение к истории развития дополнительного образования сегодня особенно актуально, так как позволяет использовать наиболее ценный опыт, накопленный в этой сфере, современным педагогам, которые на практике реализуют данное направление. В современных условиях особенно важно привлечь несовершеннолетних учащихся в структуру дополнительного образования, чтобы оградить досуг детей от негативного воздействия различных деструктивных групп.

Цель исследования определила круг приоритетных задач:

- провести сопоставительный анализ документов, регламентирующих деятельность учреждений системы дополнительного образования школьников в конце 50-х - начале 60-х годов XX века и на современном этапе развития российского образования; 
- определить возможности реализации социального заказа государства учреждениями системы дополнительного образования детей в Советском Союзе 1950-1960-х годов и в современной Российской Федерации;

- сравнить приоритетные направления развития системы дополнительного образования выбранных исторических периодов.

Исследование построено на основе метода сопоставительного анализа.

Теоретическую базу исследования составили документы, регламентирующие деятельность учреждений системы дополнительного образования школьников в конце 50-х - начале 60-х годов XX века и на современном этапе развития российского образования [7-12], а также исследования, отражающие исторические аспекты в области организации системы дополнительного образования, А. С. Анискова [1], В. П. Голованова [3], Е. А. Ефимовой и А. В. Чернышова [5], 3. А. Каргиной [6], Н. А. Соколовой [15].

Практическая значимость заключается в том, что выводы, полученные в результате работы, могут быть использованы в образовательной деятельности институтов дополнительного образования при подготовке и планировании учебной работы.

\section{Сопоставительный анализ документов, регламентирующих деятельность учреждений системы дополнительного образования школьников} в конце 50-X - начале 60-х годов XX века и на современном этапе развития российского образования

В разные исторические периоды концепция дополнительного образования реализовывалась на практике с учетом специфики стоящих перед ним задач. В нашей стране долгое время дополнительное образование не входило в государственную систему народного образования, а включало в себя профессиональные курсы, библиотеки, театры, народные университеты, публичные лекции [3, с. 69].

В 1918 году система дополнительного образования приобретает статус государственной [Там же]. С этого момента данный элемент образования начал активно реализовывать возложенный на него социальный заказ общества и государства, который находится в постоянном изменении в связи с вызовами времени.

В конце 50-X - начале 60-х годов XX века в Советском Союзе многие формы внеклассной работы стали нести особую значимость и получили огромный импульс развития [1, с. 85]. Анализируя причины таких изменений, некоторые исследователи (А. С. Анисков, Н. А. Соколова) связывают их с демократизацией общественной жизни СССР данного периода («хрущевская оттепель»), говоря о том, что в это время акцент воспитания сместился от политизации к формированию гармонично развитой личности [Там же, с. 86].

Также необходимо отметить, что в указанный период в стране шла научно-техническая революция. Ее влияние проникало во все стороны общественной жизни, включая образование. Многократно возросла роль теоретических знаний и умственного труда, существенно вырос объем научной информации, которая была необходима в повседневной жизни. Страна стала нуждаться в специалистах, которые не только могли освоить новую технику, но и постоянно повышать свои профессиональные компетенции, личностно развиваться.

Образование должно было идти в ногу с модернизационными процессами, перед ним ставилась задача воспитания личности, которая будет испытывать жажду знаний, стремление развивать и совершенствовать навыки, необходимые для успешной социализации в быстро развивающемся динамичном мире.

Данная задача не потеряла своей актуальности и сегодня. Концепция ФГОС предусматривает воспитание и развитие качеств личности, которые будут отвечать требованиям современного общества, а идея саморазвития личности является одной из центральных. В связи с этим можно отметить, что институт дополнительного образования всегда обладал огромным потенциалом для практической реализации данной идеи на практике мы можем увидеть это и в рассматриваемом периоде СССР конца 50-х - начала 60-х годов XX века, и на современном этапе развития российского образования.

Важность и значимость задач, возложенных на структуру дополнительного образования, можно проследить и в нормативных документах, регламентирующих образовательную деятельность на разных этапах его развития. Верховный совет СССР 24 декабря 1958 года принял закон «Об укреплении связи школы с жизнью и о дальнейшем развитии системы народного образования в СССР», который указывал, что, несмотря на выдающиеся достижения, советская школа имеет серьезные недостатки, которые необходимо было устранить [8]. Данный документ серьезно перестраивал существовавшую систему образования - менялись сроки обучения, изменялось соотношение теории и практики при изучении школьных дисциплин, отменялось раздельное обучение мальчиков и девочек, вводились новые типы школ. Также с учетом новых реалий перестраивалась работа учреждений среднего и высшего профессионального образования.

Закон дал импульс изменениям и в деятельности учреждений дополнительного образования. Центральный совет Всесоюзной пионерской организации вынес постановления «Об улучшении работы внешкольных учреждений в связи с законом “Об укреплении связи школы с жизнью и о дальнейшем развитии системы народного образования в СССР” (1959 г.) и «О дальнейшем развитии инициативы и самостоятельности во Всесоюзной пионерской организации им. В. И. Ленина» (1960 г.). Данные документы предполагали улучшить руководство внешкольными учреждениями путем закрепления за ними шефских комсомольских организаций и привлечения к сотрудничеству творческих и общественных организаций [6, с. 96].

Федеральный закон «Об образовании в Российской Федерации» от 29.12.2012 № 273-Ф3 подчеркивает важность дополнительного образования для успешной адаптации к жизни в обществе, творческого, 
интеллектуального, физического и нравственного развития и совершенствования детей [7]. Постановление Правительства РФ от 15.04.2014 № 295 «Об утверждении государственной программы Российской Федерации “Развитие образования” на 2013-2020 годы» указывает, что к окончанию отчетного периода не менее 75 процентов детей в возрасте от 5 до 18 лет должны быть охвачены программами дополнительного образования [9]. Приказ Министерства просвещения РФ «Об утверждении Порядка организации и осуществления образовательной деятельности по дополнительным общеобразовательным программам» указывает, что программы дополнительного образования должны ежегодно обновляться с учетом развития техники, науки, культуры, экономики, технологий и социальной сферы [10].

Таким образом, анализируя представленные документы, можно говорить о том, что государство видит в институте дополнительного образования большой потенциал для реализации своего социального заказа как в период конца 50-х - начала 60-х годов прошлого века, так и сегодня. Можно сделать вывод о том, что реализуемые программы дополнительного образования не статичны, находятся в постоянном изменении в связи с вызовами времени.

\section{Реализация социального заказа государства учреждениями системы дополнительного образования детей в конце 50-х - начале 60-х годов XX века в СССР и на современном этапе развития российского образования}

В конце 1950-х - начале 1960-х годов в Советском Союзе массово открываются дома и дворцы пионеров, на которые возлагали задачи помощи школе в проведении воспитательной работы. Работа таких учреждений была тщательно скоординирована пионерской и комсомольской организациями, а 1 июня 1962 года был открыт Московский городской дворец пионеров и школьников, который стал выполнять функции организационно-методического центра воспитательной работы дополнительного образования [6, с. 97]. Под эгидой Дворца были проведены всесоюзные акции - «Пионеры СССР - Вьетнаму», трудовая операция «Чукотка», День памяти юных героев-антифашистов и др. [Там же], а летом 1962 года здание Дворца посетили пионеры Индии, Мали, Кипра, Западного Берлина и Англии [5, с. 18].

Дворцы и дома пионеров получали от государства не только материальную, но и методическую помощь там были собраны прекрасные библиотеки, имелась бессрочная льготная подписка на передовые технические журналы Советского Союза, например «Юный техник» [14, с. 99].

Сегодня данная работа преимущественно концентрируется в специальных многопрофильных центрах дополнительного образования, которые отвечают современным требованиям безопасности, санитарного контроля и технического оснащения. Необходимо отметить, что деятельность таких центров также хорошо скоординирована органами управления образования, а проведение всевозможных акций и конкурсов федерального и даже международного уровня стало хорошей традицией. Центры дополнительного образования хорошо оснащены технически - современное учебное оборудование, стабильное и качественное интернетсоединение, открытие «Точек роста».

В СССР в конце 1950-х - начале 1960-х годов к руководству кружками и секциями привлекались не только педагогические работники, но и преподаватели вузов, студенты, представители творческой и технической интеллигенции [2, с. 75]. Они в обязательном порядке знакомились с программами, которые были рекомендованы Министерством просвещения СССР для работы во внешкольных учреждениях, методикой кружковой работы, особенностями проведения практических и лабораторных работ с участием детей [Там же]. Практики в учреждениях дополнительного образования детей вошли в учебные планы педагогических вузов Советского Союза.

Учреждения дополнительного образования современной России комплектуют штат сотрудников на конкурсной основе. Предпочтение отдается лицам, которые имеют педагогическое образование по соответствующему профилю, но даже такие сотрудники должны соответствовать перечню необходимых умений по выбранному направлению, что в значительной мере обеспечивает повышение качества дополнительного образования [11].

Работа в учреждениях дополнительного образования Советского Союза в указанные годы строилась с учетом принятого в 1958 году примерного перечня умений и навыков пионеров. Указанные в перечне компетенции в полной мере отражали социальный заказ общества и государства того времени. Данный документ дифференцировал учащихся на три возрастные группы:

- первая ступень (III-IV классы);

- вторая ступень (V-VI классы);

- третья ступень (VII-VIII классы) [13, с. 1-2].

Поскольку в ходе образовательной реформы конца 1950-х - начала 1960-х годов было отменено раздельное обучение девочек и мальчиков, дифференциация по гендерному принципу не применялась. Необходимо отметить, что, несмотря на преобладание коллективных форм трудовой и учебной деятельности, большое внимание уделялось развитию инициативы и самодеятельности обучающихся [Там же].

Современное дополнительное образование Российской Федерации при формировании учебных групп учитывает возрастные особенности детей, но применяется и более глубокая и детальная дифференциация. Работа строится с учетом познавательных возможностей учащихся - выделяются аналитический и синтетический тип восприятия; вербальное и невербальное воображение; слуховая и зрительная память; образное и понятийное мышление [4, с. 30]. Такая подробная детализация позволяет создать оптимальные условия 
для организации процесса обучения и получить более высокие результаты. Сегодня общество и государство видит в выпускнике личность, которая не только гармонически развита, но и готова к саморазвитию и овладению новыми знаниями и умениями, поэтому принцип личностно-ориентированного обучения при планировании учебной работы является одним из центральных и основополагающих.

Таким образом, сопоставив организацию работы учреждений дополнительного образования выбранных исторических периодов, можно уверенно говорить о том, что государство реализует выполнение своего социального заказа с помощью данной системы обучения. Принципы учебной работы советского периода получили дальнейшее развитие с учетом современных реалий.

\section{Приоритетные направления подготовки школьников в структуре дополнительного образования СССР конца 1950-х - начала 1960-х годов и современной России}

Характерной чертой работы организаций дополнительного образования Советского Союза 1950-1960-х годов было огромное разнообразие направлений подготовки. В эти годы было создано свыше 200 программ кружков и секций, рекомендованных Министерством просвещения СССР для работы в школьных и внешкольных учреждениях [2, с. 75]. Создаются научные общества учащихся, клубы юных экологов, краеведов, этнографов, геологов [15, с. 104]. Под влиянием научно-технической революции широкую популярность приобрели технические клубы, а также кружки радиоэлектроники, телемеханики [1, с. 86]. После того как Юрий Алексеевич Гагарин 12 апреля 1961 года открыл человечеству путь в космос, кружки и школы юных космонавтов стали пользоваться колоссальной популярностью. В 1960-х годах появляются школьные лесничества, детские автотрассы, клубы моряков, речников, полярников [6, с. 96].

Таким образом, можно сделать вывод, что в рассматриваемый период учреждениями дополнительного образования были созданы широкие условия для того, чтобы каждый советский школьник мог выбрать направление, которое соответствовало его интересам и уровню развития возрастных и познавательных процессов.

Сегодня ФГОС подразумевает реализацию основной образовательной программы основного общего образования не только через урочную, но через внеурочную деятельность [12]. В этом отношении современное дополнительное образование школьников России продолжает традиции советского прошлого и отличается широким разнообразием реализуемых программ дополнительного образования, которые можно сгруппировать по направлениям:

- художественно-эстетическое (школы искусств, художественные и музыкальные школы);

- военно-патриотическое (Юнармия, Юный друг полиции, Юный пожарный, «Щит и меч», поисковые отряды);

- физическое воспитание (детско-юношеские спортивные школы различных направлений - спортивная и художественная гимнастика, легкая атлетика, самбо, бокс, шахматы, плавание, игровые и командные виды спорта);

- интеллектуальное (углубленное изучение естественных наук, вспомогательных исторических дисциплин, практические и лабораторные занятия);

- техническое («IT-куб», робототехника, моделирование, компьютерное программирование);

- социально-педагогическое (добровольчество, волонтерство, работа с талантливыми и одаренными детьми, с детьми, имеющими ограничения по здоровью);

- туристско-краеведческое (спортивное ориентирование, изучение местной локальной истории, туристические и археологические походы, экскурсии, слеты).

Таким образом, мы можем говорить о том, что виды направлений подготовки в системе дополнительного образования школьников отличаются большим разнообразием - это можно проследить на примере СССР конца 1950-х - начала 1960-х годов и на примере современной Российской Федерации. Приоритетные направления подготовки школьников в структуре дополнительного образования изменяются и модернизируются с учетом вызовов времени.

\section{Заключение}

Проведенное исследование позволяет сделать ряд выводов.

1. Дополнительное образование является эффективным инструментом реализации социального заказа государства на разных этапах его развития.

2. Институт дополнительного образования является агентом социализации подрастающего поколения, помогая ему адаптироваться к изменяющимся условиям окружающей действительности.

3. Педагогические принципы работы с обучающимися в учреждениях дополнительного образования, заложенные советской школой, не потеряли своей актуальности, но были скорректированы с учетом современных условий. И в Советском Союзе 50-60-х гг. XX века, и в современной России в качестве основных принципов организации дополнительного образования можно выделить: общедоступность, добровольность, массовость, разнообразие форм работы, учет индивидуальных и возрастных особенностей детей.

4. Выбранные для сравнения периоды объединяет не только широкий спектр направлений, реализуемых в структуре дополнительного образования школьников, но и ориентация на развитие мыслительных качеств обучающихся, стремление развить в них навык самообразования, умение учиться. 
Перспективы дальнейшего исследования заключаются в более детальном изучении вопросов взаимодействия структуры общего и дополнительного образования школьников.

\section{Источники | References}

1. Анисков А. С. Особенности системы внешкольного воспитания детей в СССР в 1960-70-х годах // Десятилетие детства - формирование региональной политики защиты прав и законных интересов детей: сб. науч. ст. / под ред. П. В. Самылова, Е. В. Емельяновой. Калуга, 2020. С. 84-90.

2. Бурдакова А. А. История кружковой деятельности учащихся в советский период // 10 корпус. 2019. № 5. С. 70-77.

3. Голованов В. П. Исторические уроки становления и развития отечественной системы дополнительного образования детей. К 90-летию государственной системы дополнительного образования детей // Вестник Православного Свято-Тихоновского гуманитарного университета. Серия 4. Педагогика. Психология. 2009. № 1 (12). С. 69-84.

4. Дмитриева Е. С., Гельман В. Я. Восприятие эмоциональной слуховой и зрительной информации и успешность обучения младших школьников // Психологическая наука и образование. 2018. Т. 23. № 5. С. 29-39.

5. Ефимова Е. А., Чернышов А. В. Дворец - Артек: вехи истории сотрудничества // Таврический научный обозреватель. 2015. № 3: в 2-х ч. Ч. 2. С. 16-21.

6. Каргина 3. А. История становления системы дополнительного образования детей в России: два «золотых периода» // Историко-педагогический журнал. 2013. № 1. С. 89-103.

7. Об образовании в Российской Федерации [Электронный ресурс]: Федеральный закон от 29.12.2012 № 273-Ф3. Доступ из СПС «КонсультантПлюс».

8. Об укреплении связи школы с жизнью и о дальнейшем развитии системы народного образования в СССР [Электронный ресурс]: Закон от 24.12.1958 // Библиотека нормативно-правовых актов CCCP. URL: http://www.libussr. ru/doc_ussr/usr_5337.htm (дата обращения: 27.03.2021).

9. Об утверждении государственной программы Российской Федерации «Развитие образования» на 2013-2020 годы [Электронный ресурс]: Постановление Правительства РФ от 15.04.2014 № 295. Доступ из СПС «КонсультантПлюс».

10. Об утверждении Порядка организации и осуществления образовательной деятельности по дополнительным общеобразовательным программам [Электронный ресурс]: Приказ Министерства просвещения РФ от 9 ноября 2018 г. № 196. URL: https://base.garant.ru/72116730/53f89421bbdaf741eb2d1ecc4ddb4c33/\#block_1000 (дата обращения: 09.06.2021).

11. Об утверждении профессионального стандарта «Педагог дополнительного образования детей и взрослых» [Электронный ресурс]: Приказ Минтруда России от 05.05.2018 № 298н. URL: http://www.consultant.ru/ document/cons_doc_LAW_305809/64660ea348795bec850218edf727c3e27a2831a8/ (дата обращения: 10.06.2021).

12. Об утверждении федерального государственного стандарта основного общего образования [Электронный ресурс]: Приказ Министерства образования и науки Российской Федерации № 1897 от 17.12 .2010 // Информационно-правовой портал «Гарант.ру». URL: https://www.garant.ru/products/ipo/prime/doc/55070507/ (дата обращения: 10.06.2021).

13. Примерный перечень умений и навыков пионеров // Молодой ленинец. 1958. 1 августа.

14. Семивеличенко Е. А., Иванова А. Д., Муругова О. В. Вопросы профессиональной ориентации и воспитания инженерно-технических интересов молодежи и предложения по развитию журнала «Юный техник» (по результатам экономического и педагогического исследований, проведенных для «Союза машиностроителей России») // Вестник Алтайской академии экономики и права. 2019. № 7: в 2-х ч. Ч. 2. С. 98-106.

15. Соколова Н. А. Историко-педагогический анализ развития системы дополнительного образования детей в России // Вестник Челябинского государственного педагогического университета. 2015. № 9. С. 102-106.

\section{Информация об авторах | Author information}

RU Дьячин Алексей Сергеевич

${ }^{1}$ Балашовский институт

Саратовского национального исследовательского государственного университета имени Н. Г. Чернышевского

EN Dyachin Aleksey Sergeyevich

${ }^{1}$ Balashov Institute of Saratov State University named after N. G. Chernyshevskii

${ }^{1}$ djachiny@yandex.ru

\section{Информация о статье | About this article}

Дата поступления рукописи (received): 15.05.2021; опубликовано (published): 30.06.2021.

Ключевые слова (keywords): дополнительное образование; социальный заказ государства; социализация личности; нормативные документы; организация образовательного процесса; additional education; government social-sector procurement; individual's socialisation; normative documents; educational process organisation. 